\section{Mobile Applications for Patient-centered Care Coordination: A Review of Human Factors Methods Applied to their Design, Development, and Evaluation}

\author{
M. T. Baysari'1,2, J. I. Westbrook ${ }^{1}$ \\ 1 Centre for Health Systems \& Safety Research, Australian Institute of Health Innovation, Macquarie \\ University, Australia \\ 2 Department of Clinical Pharmacology \& Toxicology, St Vincent's Hospital, Sydney, Australia
}

\section{Introduction}

In the United States, $90 \%$ of adults use mobile phones, $58 \%$ use a smartphone, and over half of the adult population owns a tablet device [1]. This situation is not unique to the US. In Australia, $65 \%$ of the population owns a smartphone, and this proportion is rising rapidly: in May 2012, 8.7 million Australians owned a smartphone, in May 2013 , this number increased by $29 \%$ to reach 11.9 million [2]. Similarly in Europe, the number of smartphone users grew by $30 \%$ over 2012-2013 [3].

With the rapid uptake and use of smartphone technology, it is not surprising that there has been a surge in the development of mobile applications (apps) for health. The number of mobile health applications currently available is estimated to be over 100,000 [4]. Many of these apps are designed to be used by patients with chronic diseases $(31 \%)$, and those interested in health and fitness $(28 \%)$, or by healthcare providers (14\%) [4]. The functions or features of mobile health apps are many and varied, including for example, reminders and prompts to stay on track with medications, medical reference material and resources, the ability to track and display patients' health parameters, locate near-by doctors and pharmacies, and diaries (for patients to record symptoms, feelings, food, alcohol and medication intake).

Research has shown that consumers are open to using mobile technology for health management and education $[5,6]$. For example, a survey administered to teenagers and parents/caregivers at pediatric clinics in the US revealed that most owned a smartphone (84\%) and most were interested in using medical apps [5]. Similarly, $35 \%$ of outpatient mental health patients older than 60 years owned a smartphone and $71 \%$ indicated they were interested in using a mobile application to track their mental health condition [6].

With the explosive increase in the number of mobile applications becoming available to consumers and health professionals, concerns have been raised about the quality and effectiveness of the systems developed [7]. It has been suggested that many apps are being made available to the public in the absence of systematic or rigorous approaches to design, development, or evaluation [8]. As a result, the use, usability and value of many mobile apps may be less than ideal.

Human Factors could significantly contribute to the enhanced design, use and evaluation of mobile apps. Human Factors is the discipline that applies evidence-based methods and knowledge about people to design, evaluate, and improve the interaction between people, systems (including technology), and organizations. Human Factors has received much attention within the field of medical informatics over the last decade, as its importance is increasingly being recognized and its methods applied. For example, The International Journal of Medical Informatics published a special issue on 'Human factors and the implementation of health information technology' in 2013, and inputting the term 'human factors' into The Journal of the American Medical 
Informatics Association's search box in May 2015 identified 2030 articles.

Human factors is relevant to all stages of technology design, development, and evaluation. Adopting a user-centered approach to technology design is clearly an important element in increasing the likelihood of the fit between people and the technology. Human factors researchers have an armory of data collection (typically user interviews, questionnaires, and in situ and lab-based observations), and analysis methods (e.g. task analysis, process charting, heuristic analysis) [9] to establish the fit between a system (e.g. technology) and its user. These techniques are also useful in the post-implementation evaluation stage when applied to the observation of actual users in naturalistic settings.

Improving care coordination has been identified as one of the greatest potential benefits of information technology in terms of improving quality, safety and efficiency of care [10]. Patient-centered care coordination goes one step further by placing patients at the center to increase their engagement in this care coordination process. The US Agency for Healthcare Research and Quality defines care coordination as "deliberately organizing patient care activities and sharing information among all participants concerned with a patient's care to achieve safer and more effective care". Patient-centered care coordination not only involves positioning patient preferences, needs and values at the center of this coordinated process but increasing patient engagement and participation in their care coordination.

Mobile applications are increasingly targeting patient engagement in aspects of their care coordination. However, the extent to which developers of these applications adopt human factors approaches and methods in the design, development, or evaluation stages has been poorly studied. Establishing and ensuring that there is a good fit between the app's intended users and the technology will result in an app that is usable, accessible and useful. In this review paper, we present an overview of recent research papers (20132014) reporting on mobile applications designed to facilitate aspects of patient-centered care coordination. We aimed to examine what human factors methods, if any, were applied to the design, development and evaluation of these mobile applications.

\section{Method}

We searched MEDLINE and EMBASE for studies describing the design or the evaluation of a patient-centered mobile application. We combined [MeSH term 'mobile application' or keyword 'mhealth' or keyword 'mobile app*'] with [keyword 'patient' or keyword 'consumer'] and limited our search to papers published in 2013 and 2014. Our search resulted in a total of 538 potentially relevant papers.

To be included in our review, papers had to report on the design, development or evaluation (in practice) of a mobile application for patients, which aimed to facilitate some aspect of care coordination (e.g. patient engagement, communication). We excluded reviews, commentaries, letters and conference abstracts. We excluded papers that simply described the features of an application or compared various applications on features. To ensure that the included applications aimed to improve patient-centered care coordination, we excluded papers that reported on mobile applications that were not for patient use (e.g. apps for doctors with no patient functions), or apps that did not allow patients to view or access their personal information (e.g. apps that monitored a patient's condition and transmitted this information to providers but not patients). We also excluded papers that reported on apps for delivering treatment or large-scale information systems (e.g. an artificial pancreas), where a smart phone was used as the processing platform, and consumers were not able to use their mobile device for normal functions (e.g. making calls).

Titles and abstracts of the 538 papers were first screened to reject non-relevant papers. This resulted in the exclusion of 405 papers. The remaining 133 papers were read in full to determine if they met our inclusion criteria. Any disagreements or difficult cases were discussed amongst the two authors until a consensus was reached. This resulted in the inclusion of 34 papers for our analysis.

All selected papers were reviewed to identify if a human factors approach and methods had been applied to investigate the fit between the technology and the patient in terms of the design, development, or evaluation of the app.

\section{Results}

Of the 34 papers that met our inclusion criteria, 15 papers reported on the design or development of a mobile application, and 16 papers reported on the evaluation of an app in practice. Three studies reported on both the design and evaluation of a mobile application.

\section{Design and Development}

A brief description of the mobile applications, and the methods used in the 15 papers reporting on design or development are displayed in Table 1. All applications (but two $[11,12])$ were specific to a disease or condition (e.g. diabetes, asthma).

Twelve of the 15 papers describing the process of design or development of an app adopted a human factors approach. The most frequently used methods were interviews and surveys, which often included an exploration of participants' current use of information technology, including mobile apps [11, 1319]. Some studies included multiple components and methods, often generating rich data on patients' views and use. For example, Ben-Zeev et al (2013), in their development of an application for people with schizophrenia, adopted a user-centered approach including three complementary methods: 1) a needs assessment based on a survey administered to people with schizophrenia, 2) interviews with practitioners, and 3 ) usability testing (including think-aloud) with 12 people with schizophrenia [19]. Survey and interview results were used to generate a list of functions to include in the application. Following prototype development, their user testing demonstrated that patients were able to learn how to use the application quickly, but user testing also identified a range of potential design issues (e.g. difficult abbreviations, poor display of touchscreen buttons) which needed to be addressed to improve usability [19].

In another study that adopted a participatory design approach for a diabetes app [16], researchers initially held in-depth semi-structured interviews with their target users (young people aged 18-21 with diabetes) to understand their everyday experience of diabetes and to explore their current use and views 
of technology. Based on interview findings, several requirements were identified and three prototype applications were developed: 1) an app to educate patients on diabetes in general, 2) an app to educate patients on alcohol use in diabetes, and 3) an app to educate patients on hypoglycemia. These prototypes were then shared with another group of young diabetic patients. Patients were observed using each of the prototypes. They also provided feedback on each prototype during the interviews. Based on user input, the app for alcohol education was selected for final development. Feedback from patients and clinic staff was incorporated into subsequent iterations of the mobile application until developers were confident that the product was user friendly and met all user needs [16].

Three studies did not describe a human factors approach to design or development; however, the research did not appear to be at odds with this approach. Instead, the studies reported on a complementary aspect of development. In one case, researchers performed an ex-ante economic evaluation of a mobile application to estimate the reduction in management and treatment costs associated with the implementation of an app to support self-management of heart diseases [20]. In the other cases, researchers measured the accuracy of an app to recognize coughing symptomatic of asthma [21], and assessed the capacity of an app to perform an EEG scan (i.e. compared the brain activity captured by the app to that obtained with standard EEG equipment) [12].

\section{Evaluations in Practice}

As shown in Table 2, 16 papers reported on the evaluation of a patient health application in practice. All studies reporting evaluations adopted a human factors approach to some extent. In many papers $(n=10)$, evaluation comprised an examination of the use of application features (e.g. documentation of symptoms). For example, in the evaluation of an app to assist patients in medication management, the frequency and intensity of application use was tracked to explore the use of the app over time [29]. The authors found that after one year, only $1 \%$ of users were regularly using the application (i.e. they used the app at least once a week). In the evalua- tion of an app for children and young adults with type 1 diabetes, click stream data were analyzed to examine user interactions with the app and their communication with peers using the app [30]. The authors reported that most users regularly exchanged comments with peers, notifying their friends of what they ate, their blood glucose level, their mood, and the activities they participated in.

Another common approach for assessing mobile apps was to elicit the views of users, via a survey or interviews. In the evaluation of an application designed to support communication between teenagers with asthma and nurses, both patients and nurses were interviewed following pilot testing. Patients reported that using the application had improved their access to nurses, they were feeling more comfortable communicating with nurses via the app than over the telephone and most patients indicated that the app had improved their relationship with their nurse. Nurses felt that the application had allowed patients to more actively engage in their care, and that it provided patients with an avenue for honest communication [31]. In a randomized controlled trial of an application for young people with mental health problems, both general practitioners (GPs) and patients completed surveys following the trial to explore perceived effectiveness of the app and its impact on doctor-patient rapport [32]. GPs reported that the app assisted them in gaining an accurate picture of their patient's current condition, in diagnosing and in communicating with patients. However, patients who used the app reported equivalent levels of doctor-patient rapport to patients who did not use the app.

None of the studies included in our review assessed the impact of mobile application use on health outcomes, although one study demonstrated increased knowledge of pap testing following the use of an educational app [33].

\section{Studies Reporting Design and Evaluation}

A brief description of the mobile applications and methods used in the three papers reporting on both design/development and evaluation appears in Table 3.
All papers adopted a human factors approach to design/development of the app, and all included a survey to assess user views of the app as part of their evaluation. In one case, patients also reported better treatment adherence and a lower rate of missed doses when using an app designed to support medication management [46]. In another study, the use of an app designed to educate women on long-acting contraceptive methods while they were waiting in a clinic waiting room was associated with increased knowledge and interest in long-acting contraceptive methods [47].

\section{Discussion}

\section{Human Factors Approach to Design, Development, and Evaluation}

Human factors methods and approaches are increasingly being used to inform the design and assessment of large-scale health information technologies (e.g. decision support systems [49], barcode medication administration systems [50]). In this review, we observed that human factors approaches are also being widely applied to the design, development, and evaluation of patient-centered mobile applications. However, we identified only three studies that reported on both the design and subsequent evaluation of a mobile application, making it difficult to determine whether adopting a human factors approach to design results in applications that are more useful, usable or used (i.e. results in a good fit between user and technology). Previous research has shown that user involvement in system development can lead to greater utilization of the system, and greater satisfaction with the system [51], but we found no attempt to establish this relationship with mobile applications. Research demonstrating the potential benefits of seeking user input early in the development process is clearly needed.

Interestingly, the majority of apps described in the papers included in the review targeted one condition or disease. The Centers for Disease Control and Prevention in the US recently reported that $21 \%$ of adults 
Table 1 Papers published in 2013-2014 that reported on the design or development of a patient mobile health application to support an aspect of care coordination

\begin{tabular}{|c|c|c|}
\hline Study & Mobile application & Methods used to design/develop \\
\hline $\begin{array}{l}\text { Buller, } 2013 \\
{[15]}\end{array}$ & $\begin{array}{l}\text { Solar Cell- provides personalized real-time advice to } \\
\text { help people manage sun safety }\end{array}$ & $\begin{array}{l}\text { 1. Focus groups with adults to identify useful features of a mobile app } \\
\text { 2. Usability testing with a prototype mobile application (think aloud while completing scenarios using the app and a post-trial survey) } \\
\text { 3. Usability testing repeated with the fully developed mobile application }\end{array}$ \\
\hline $\begin{array}{l}\text { Burnay, } 2013 \\
{[22]}\end{array}$ & $\begin{array}{l}\text { m.Carat- supports self-management of asthma and } \\
\text { allergic rhinitis }\end{array}$ & 1. Eight users performed 10 standardized tasks using the app and reported any difficulties \\
\hline $\begin{array}{l}\text { Cano Martin, } \\
2014[20]\end{array}$ & $\begin{array}{l}\text { Cardiomanager-supports self-management of heart } \\
\text { diseases }\end{array}$ & 1. Cost effectiveness study \\
\hline $\begin{array}{l}\text { De La Vega, } \\
2014 \text { [23] }\end{array}$ & Painometer - allows users to assess pain intensity & $\begin{array}{l}\text { 1. User testing with healthcare professionals and non-professionals (think aloud while using system, and post-trial interviews) } \\
\text { 2. Survey of healthcare professionals and non-professionals on previous use of technology } \\
\text { 3. Several changes were made to the app and usability testing was repeated }\end{array}$ \\
\hline $\begin{array}{l}\text { Klein, } 2014 \\
{[24]}\end{array}$ & $\begin{array}{l}\text { eMate - coaches patients with diabetes, HIV or } \\
\text { cardiovascular disease to support their adherence to therapy }\end{array}$ & $\begin{array}{l}\text { 1. Survey of healthy subjects to measure physical activity behavior and possible determinants } \\
\text { 2. Survey of patients with chronic conditions to measure physical activity behavior, healthy diet behaviors and their } \\
\text { possible determinants } \\
\text { 3. Comparison of conclusions and answers to questions provided by patients in survey } \\
\text { 4. Simulation - answers from survey were inputted into app and outputs were compared to other survey answers }\end{array}$ \\
\hline $\begin{array}{l}\text { Macpherson, } \\
2014[25]\end{array}$ & $\begin{array}{l}\text { C-SCAT-allows recording of symptoms (and clusters of } \\
\text { symptoms) by adolescents and young adults with cancer }\end{array}$ & $\begin{array}{l}\text { 1. User testing to evaluate user experience of using C-SCAT to record symptoms } \\
\text { 2. Survey of users to assess acceptability of tool }\end{array}$ \\
\hline $\begin{array}{l}\text { Pulman, } 2013 \\
{[16]}\end{array}$ & $\begin{array}{l}\text { Provides diabetes education about alcohol for young } \\
\text { patients with type } 1 \text { diabetes }\end{array}$ & $\begin{array}{l}\text { 1. In-depth interviews of type } 1 \text { diabetes patients to explore their experiences and usage of mobile technology, their } \\
\text { day-to-day life with diabetes, and ideas for app design } \\
\text { 2. Prototype ideas were discussed with patients in later interviews } \\
\text { 3. Questionnaire administered to clinical staff to obtain feedback on the prototype }\end{array}$ \\
\hline $\begin{array}{l}\text { Sanger, } 2014 \\
{[26,27]}\end{array}$ & $\begin{array}{l}\text { App to improve the identification and management of } \\
\text { post-discharge surgical site infections }\end{array}$ & $\begin{array}{l}\text { 1. Interviews (critical incident technique) with patients who had post-discharge complications after undergoing surgery to } \\
\text { explore challenges in managing post-discharge wound complications } \\
\text { 2. Survey of patients who had post-discharge complications after undergoing surgery to assess acceptability of a } \\
\text { paper-based mock-up of an app to assist with wound monitoring }\end{array}$ \\
\hline $\begin{array}{l}\text { Shah, } 2014 \\
{[17]}\end{array}$ & $\begin{array}{l}\text { SMART-allows patients with sickle cell disease to } \\
\text { record and access key disease-related clinical symptoms, } \\
\text { including pain }\end{array}$ & $\begin{array}{l}\text { 1. Telephone survey of patients with sickle cell disease to explore current use of information technology, particularly } \\
\text { mobile devices } \\
\text { 2. Survey of patients who trialed the app to evaluate usability, utility and practicality of the app }\end{array}$ \\
\hline $\begin{array}{l}\text { Sterling, } 2014 \\
{[21]}\end{array}$ & $\begin{array}{l}\text { ADAM - Automated system for asthma monitoring. } \\
\text { Continually monitors coughing in adolescent asthma patients }\end{array}$ & $\begin{array}{l}\text { 1. Recorded audio data from a large number of asthma patients to train, and validate, the software to recognize } \\
\text { symptomatic sounds }\end{array}$ \\
\hline $\begin{array}{l}\text { Stinson, } 2014 \\
{[13]}\end{array}$ & $\begin{array}{l}\text { iCanCope with Pair }{ }^{T M} \text { - self management program for } \\
\text { adolescents with chronic pain }\end{array}$ & $\begin{array}{l}\text { 1. Focus groups with adolescents and healthcare providers specialized in the management of chronic pain to explore } \\
\text { experiences and healthcare needs } \\
\text { 2. A proposed architecture for the app was developed based on focus group findings } \\
\text { 3. In-depth interviews of adolescents to collect feedback on the acceptability and perceived value of the core features of the app }\end{array}$ \\
\hline $\begin{array}{l}\text { Stopczynski, } \\
2014[28]\end{array}$ & $\begin{array}{l}\text { Smartphone brain scanner - fully portable } 3 D \text { EEG } \\
\text { imaging system that records brain activity via a cap } \\
\text { placed over the head }\end{array}$ & $\begin{array}{l}\text { 1. Data extracted from device to determine sampling rate, delays, stability and quality of signals } \\
\text { 2. Data extracted from device to evaluate output during finger tapping }\end{array}$ \\
\hline
\end{tabular}


Mobile Applications for Patient-centered Care Coordination: A Review of Human Factors Methods Applied to their Design, Development, and Evaluation

Table 2 Papers published in 2013-2014 that reported on the evaluation (in practice) of a patient mobile health application to support an aspect of care coordination

\begin{tabular}{|c|c|c|}
\hline Study & Mobile application & Methods used to evaluate \\
\hline $\begin{array}{l}\text { Becker, } \\
2013[29]\end{array}$ & $\begin{array}{l}\text { Medication plan-allows users to maintain and alter a } \\
\text { drug therapy plan (includes medication reminders) and } \\
\text { document vital signs }\end{array}$ & $\begin{array}{l}\text { 1. Tracking the use of the app (frequency and intensity of app use) } \\
\text { 2. Anonymous on-line survey to evaluate the demographic profile of users } \\
\text { 3. Review of feedback emails from users }\end{array}$ \\
\hline $\begin{array}{l}\text { Christensen, } \\
2014[33]\end{array}$ & $\begin{array}{l}\text { MyPapp- educates women on many aspects of Pap } \\
\text { testing, specifically focusing on common misconceptions } \\
\text { about the test }\end{array}$ & $\begin{array}{l}\text { 1. Survey of women aged } 18-25 \text { years to assess knowledge about Pap tests pre and post app distribution (Intervention } \\
\text { group) or pre and post pamphlet distribution (Control group) } \\
\text { 2. Survey of women aged } 18-25 \text { years (in Intervention group) to assess experience with using the app }\end{array}$ \\
\hline $\begin{array}{l}\text { DeVito } \\
\text { Dabbs, } \\
2013[34]\end{array}$ & $\begin{array}{l}\text { Pocket PATH - promotes the performance of self-care } \\
\text { behaviors among transplant patients with chronic illness }\end{array}$ & $\begin{array}{l}\text { 1. RCT to compare the effect of Pocket PATH vs standard care on self-care behaviors (e.g. adherence), and transplant-relat- } \\
\text { ed health (e.g. readmissions) in patients following a lung transplant (paper presents study protocol, not results) } \\
\text { 2. Questionnaires were administered to patients following the use of app to assess technology acceptance, satisfaction, } \\
\text { and ease of use } \\
\text { 3. Data on the use of app was uploaded from each device over the course of the study }\end{array}$ \\
\hline $\begin{array}{l}\text { Forman, } \\
2014[35]\end{array}$ & Heart Coach-supports cardiac rehabilitation & $\begin{array}{l}\text { 1. Patients used the app for } 30 \text { days, data on use was collected by the app, and a daily survey was delivered to } \\
\text { patients via the app to assess their experience of using the app } \\
\text { 2. Survey of cardiac rehabilitation staff who monitored patients via a web-based dashboard during the trial }\end{array}$ \\
\hline $\begin{array}{l}\text { Goldberg, } \\
2014[36]\end{array}$ & $\begin{array}{l}\text { PatientTouch-allows ED patients to self-administer a } \\
\text { clinical history }\end{array}$ & $\begin{array}{l}\text { 1. Survey of ED patients with } 1 \text { of } 6 \text { chief complaints who used the device to evaluate user perceptions of the physical } \\
\text { features of the device, completeness of the program, ease of use, potential impact, and overall satisfaction }\end{array}$ \\
\hline $\begin{array}{l}\text { Haze, } 2013 \\
{[37]}\end{array}$ & $\begin{array}{l}\text { Supports self-management of illness by teenagers with } \\
\text { asthma, connects patients from their point-of-living to a } \\
\text { primary care representative (RN coordinator) }\end{array}$ & $\begin{array}{l}\text { 1. Usage data extracted from data logs from the smart-phone application } \\
\text { 2. Surveys of patients (teenagers with asthma) at base-line, bi-monthly and at the completion of the pilot } \\
\text { 3. Semi-structured interviews with patients and RN coordinators following the trial to explore the impact of the app on } \\
\text { the patient-RN relationship and any barriers to its use }\end{array}$ \\
\hline $\begin{array}{l}\text { Helander, } \\
2014[38]\end{array}$ & The Eatery - supports healthy eating & 1. Anonymous usage data obtained from app developer to examine use of features \\
\hline $\begin{array}{l}\text { Kuhn, } 2014 \\
{[39]}\end{array}$ & $\begin{array}{l}\text { PISD Coach- assists trauma survivors in the manage- } \\
\text { ment of post-traumatic stress symptoms }\end{array}$ & $\begin{array}{l}\text { 1. Survey of users to assess satisfaction and perceived helpfulness of the app } \\
\text { 2. Focus group with users to evaluate app use, perceived value, and impact on health management }\end{array}$ \\
\hline $\begin{array}{l}\text { Layton, } \\
2014[40]\end{array}$ & $\begin{array}{l}\text { Wellframe- assists patients with coronary heart disease } \\
\text { or congestive heart failure to transition to outpatient care } \\
\text { after discharge from hospital }\end{array}$ & $\begin{array}{l}\text { 1. Usage data extracted from data logs from the smart-phone application } \\
\text { 2. Patients were phoned on a weekly basis to confirm appointments, determine if they had been hospitalized, and ask } \\
\text { about app usefulness }\end{array}$ \\
\hline $\begin{array}{l}\operatorname{lin}, 2014 \\
{[41]}\end{array}$ & $\begin{array}{l}\text { Dental Calendar - allows users to make appointments } \\
\text { and record symptoms. App also sends reminders and } \\
\text { allows dentists to send messages to patients }\end{array}$ & 1. Survey of dentists and patients before and after use of app to explore user experience of the app \\
\hline $\begin{array}{l}\text { Min, } 2014 \\
{[42]}\end{array}$ & $\begin{array}{l}\text { Pit-a-Pat-Allows the recording of sleep disturbances, } \\
\text { anxiety severity, and mood for breast cancer patients } \\
\text { receiving chemotherapy }\end{array}$ & $\begin{array}{l}\text { 1. Evaluation of patient-level reporting (i.e. the days self-reporting was completed) during a } 90 \text { day trial of the app } \\
\text { 2. At the end of the trial, participants were asked (via the app) to report reasons for missing self-reporting }\end{array}$ \\
\hline $\begin{array}{l}\text { Padman, } \\
2013[30]\end{array}$ & $\begin{array}{l}\text { Supports children and young adults with Type } 1 \text { diabetes } \\
\text { self-manage their condition }\end{array}$ & $\begin{array}{l}\text { 1. Usage data extracted from app, specifically health metric data (e.g. activity and glucose), comments data (i.e. } \\
\text { comments exchanged between users) and click stream data (i.e. features used) }\end{array}$ \\
\hline $\begin{array}{l}\text { Reid, } 2013 \\
{[32]}\end{array}$ & $\begin{array}{l}\text { Mobiletype- tracks young people's experiences } \\
\text { with mental problems to help doctors in determining } \\
\text { appropriate treatment approaches and management plans }\end{array}$ & $\begin{array}{l}\text { 1. Survey of GPs to assess the extent to which the tool assisted them, and of patients to understand the patient's } \\
\text { current functioning } \\
\text { 2. Survey of GPs pre and post trial to assess GP confidence } \\
\text { 3. Survey of patients pre and post trial to evaluate doctor-patient rapport } \\
\text { 4. Exit interview conducted with patients to assess pathways to care (e.g. if they were prescribed medications) }\end{array}$ \\
\hline $\begin{array}{l}\text { Tatara, } \\
2013 \text { [43] }\end{array}$ & $\begin{array}{l}\text { The Few Touch Application (FTA)- supports patient } \\
\text { self-management of Type } 2 \text { diabetes (includes a blood } \\
\text { glucose meter) }\end{array}$ & $\begin{array}{l}\text { 1. Usage data extracted from device } \\
\text { 2. Survey of users to determine their change in self-management activity with app, and app usability } \\
\text { 3. Focus group with users to explore usability in more depth }\end{array}$ \\
\hline $\begin{array}{l}\text { Tseng, } 2014 \\
{[44]}\end{array}$ & $\begin{array}{l}\text { Supports elderly outpatients manage medications (app } \\
\text { is one component of a medication management system, } \\
\text { including bar coded medications, a pill box, and a website) }\end{array}$ & 1. Survey of 20 elderly patients who used the system for 2 weeks to assess acceptability \\
\hline $\begin{array}{l}\text { Tsui, } 2014 \\
\text { [45] }\end{array}$ & $\begin{array}{l}\text { SightBook'I - allows diabetic patient self-measurement } \\
\text { of vision and facilitates coordination of patient, diabetol- } \\
\text { ogist and ophthalmologist to control diabetic retinopathy } \\
\text { risk factors, and timing of ophthalmology treatment }\end{array}$ & $\begin{array}{l}\text { 1. Online questionnaires to assess patient-reported outcomes including depressive symptoms, perceived competence in } \\
\text { managing diabetes, and illness perceptions regarding diabetes. Main study outcome was completion of question- } \\
\text { naires at baseline, and use of the tool }\end{array}$ \\
\hline
\end{tabular}




\begin{tabular}{|c|c|c|}
\hline Study & Mobile application & Methods used to develop/evaluate \\
\hline $\begin{array}{l}\text { Gu0, } 2013 \\
{[48]}\end{array}$ & $\begin{array}{l}\text { Assists diabetes patients in the self } \\
\text { management of their disease (e.g. exercising) }\end{array}$ & $\begin{array}{l}\text { 1. 'Self-care theory', relevant literature, and the Taiwan Association of Diabetes were used to develop a set of initial } \\
\text { app functions } \\
\text { 2. These prototypes were tested by an educator, a senior nurse, and three outpatients before a final version was } \\
\text { confirmed } \\
\text { 3. } 27 \text { diabetes patients used the app for a } 6 \text {-week period and usage data was extracted from devices following } \\
\text { completion of trial } \\
\text { 4. Survey of patients' acceptance of the app }\end{array}$ \\
\hline $\begin{array}{l}\text { Mira, } 2014 \\
{[46]}\end{array}$ & $\begin{array}{l}\text { ALICE - supports medication self- } \\
\text { management in elderly patients }\end{array}$ & $\begin{array}{l}\text { 1. Focus groups with patients and professionals (physicians and pharmacists) to inform app design } \\
\text { 2. User testing with } 8 \text { elderly patients to identify any problems with using the app } \\
\text { 3. RCT - patients completed a survey pre and post use of app (or no app) to assess treatment adherence, missed } \\
\text { doses, and medication errors } \\
\text { 4. Survey of patients who used the app to evaluate performance, usability, reliability, usefulness, and overall } \\
\text { satisfaction with the app }\end{array}$ \\
\hline
\end{tabular}

aged $45-64$ and $45 \%$ of adults aged over 65 have two or more chronic conditions [52]. In Australia, over $50 \%$ of people aged $>50$ years have at least two chronic conditions [53]. These figures bring to mind the question of whether designers of mobile health applications should be developing systems for patients with multiple conditions. Do we expect patients to use different medical applications for each of their conditions? An ideal app for facilitating patient-centered care coordination would be one that allowed patients to manage and track all their conditions (e.g. allowed documentation of symptoms for all conditions, triggered reminders for all medications, not just those for diabetes, for example). An app that is able to provide feedback about the interactions between an individual's conditions and treatments could provide insights to allow patients to develop effective strategies for managing their health in a more holistic fashion. Such an app could be used to target clinical specialist silos, allowing patients to provide their clinicians with ongoing information about how a multiplicity of variables affect their health, not just information relating to a single condition and treatment. This surely would be a step towards more patient-centered care coordination. We didn't find any medical application in our review that attempted to tackle the reality of patients with multiple system health problems.

\section{Mobile Applications to Support Patient-centered Care Coordination}

Patient-centered care coordination places consumers in a position where they have control of, and information about, their care to the level desired to deliver quality outcomes. Research investigating effective chronic disease management has shown that multi-component interventions are required to support patient-centered care coordination [54]. These include elements such as organizational changes to the way health provider teams work and interact with patients, strategies that support patient engagement, and access to useful and relevant information for both providers and patients. Potential barriers to patient-centered coordination, particularly care planning during health care consultations, include poor health literacy, level of assertiveness and numeracy skills, along with a patient's emotional state [55]. Mobile applications are thus considered as potentially very useful tools for supporting patient-centered care coordination by facilitating new ways in which patients and providers can interact, and for providing access to information in a format tailored to patients' needs. Importantly, the mobility of these interventions is key to allowing patients to engage or participate, and communicate outside formal health care consultations.

A key question is what methods are appropriate for assessing care coordination and measuring any possible changes to coordination following intervention implementation? In this review, we identified the two most common methods for app evaluation to be tracking of application use and patient surveys. Does the use of a mobile app feature equate to increased participation or engagement in one's condition? Does a patient's experience of improved communication with providers translate to detectable improvements in care coordination? And does this really matter, or are perceived improvements enough? In this review we did not identify any paper that went beyond app utilization or patient surveys to investigate the impact of mobile application use on health outcomes.

\section{Limitations of the Study}

A major challenge for our review was the inconsistent ways in which terms related to both 'patient-centered' and 'care-coordination' are used and defined. We thus 
used a range of strategies to identify papers reporting mobile applications that aimed to make some contribution to patients' active involvement in the coordination of their care, but may not have captured all papers. We applied a fairly generous definition of a 'human factors approach', that is, use of methods such as surveys and interviews, were classified as a human factors approach. However the extent to which the researchers/designers had a good knowledge of human factors principles and were able to apply the information gained was often not possible to determine.

\section{Conclusions}

Overall, the potential of mobile health applications to assist patients and providers in coordinating care has resulted in a large number of applications being developed to facilitate patient participation and communication. Our review of 2013-2014 papers showed that human factors approaches are nearly always adopted in the design, development, and evaluation of mobile applications. Evaluations of health applications that include an assessment of health outcomes would strengthen the evidence base for mobile application use to improve care coordination.

\section{References}

1. Pew Research Internet Project. Mobile technology fact sheet. 2014. http://www.pewinternet.org/factsheets/ mobile-technology-fact-sheet/ (accessed 12th Nov 2014).

2. acma. Communicatons report 2012-13: Australian Communications and Media Authority, Australian Government; 2013.

3. Schindler S. Smartphones reach majority in all EU5 countries; 2013. http://www.comscore.com/ Insights/Data-Mine/Smartphones-Reach-Majority-in-all-EU5-Countries (accessed 12th Nov 2014).

4. research2guidance. mHealth App Developer Economics 2014. Germany: research2guidance; 2014.

5. Singh A, Wilkinson S, Braganza S. Smartphones and pediatric apps to mobilize the medical home. J Pediatr 2014;165(3):606-10.

6. Torous J, Friedman R. Smartphone use among patients age greater than 60 with mental health conditions and willingness to use smartphone applications to monitor their mental health conditions. Am J Geriatr Psychiatry 2014;( 1): S128-S9.

7. Pelletier S. Explosive growth in health care apps raises oversight questions. 2012. https:// http://www.aamc.org/newsroom/reporter/october2012/308516/health-care-apps.html (accessed 20 November 2013).

8. Nilsen W, Kumar S, Shar A, Varoquiers C, Wiley T, Riley WT, et al. Advancing the science of mHealth. J Health Commun 2012;17 Suppl 1:5-10.

9. Stanton NA, Hedge A, Brookhuis K, Salas E, Hendrick H, editors. Handbook of Human Factors and Ergonomics Methods. Florida: CRC Press; 2005.

10. Nguyen L, Bellucci E, Nguyen LT. Electronic health records implementation: An evaluation of information system impact and contingency factors. Int J Med Inform 2014;83(11):779-96.

11. Hayakawa M, Uchimura Y, Omae K, Waki K, Fujita H, Ohe K. A smartphone-based medication self-management system with realtime medication monitoring. Appl Clin Inform 2013;4(1):37-52.

12. Stopczynski A, Stahlhut C, Larsen JE, Petersen MK, Hansen LK. The smartphone brain scanner: a portable real-time neuroimaging system. [Erratum appears in PLoS One. 2014;9(4):e96652]. PLoS ONE [Electronic Resource] 2014;9(2):e86733.

13. Stinson JN, Lalloo C, Harris L, Isaac L, Campbell F, Brown S, et al. ICanCope with Pain ${ }^{\mathrm{TM}}$ : User-centred design of a web- and mobile-based self-management program for youth with chronic pain based on identified health care needs. Pain Res Manag 2014;19(5):257-65.

14. Ben-Zeev D, Kaiser SM, Brenner CJ, Begale M, Duffecy J, Mohr DC. Development and usability testing of FOCUS: a smartphone system for self-management of schizophrenia. Psychiatric Rehabil J 2013;36(4):289-96.

15. Buller DB, Berwick M, Shane J, Kane I, Lantz K, Buller MK. User-centered development of a smart phone mobile application delivering personalized real-time advice on sun protection. Transl Behav Med 2013;3(3):326-34.

16. Pulman A, Hill J, Taylor J, Galvin K, Masding MG. Innovative mobile technology alcohol education for young people with type 1 diabetes. Practical Diabetes 2013;30(9):376-9a.

17. Shah N, Jonassaint J, De Castro L. Patients welcome the Sickle Cell Disease Mobile Application to Record Symptoms via Technology (SMART). Hemoglobin 2014;38(2):99-103.

18. Hayakawa M, Uchimura Y, Omae K, Waki K, Fujita H, Ohe K. A smartphone-based medication self-management system with realtime medication monitoring. Appl Clin Inform 2013;4(1):37-52.

19. Ben-Zeev D, Kaiser SM, Brenner CJ, Begale M, Duffecy J, Mohr DC. Development and usability testing of FOCUS: a smartphone system for self-management of schizophrenia. Psychiatric Rehabil J 2013;36(4):289-96.

20. Cano Martin JA, Martinez-Perez B, de la TorreDiez I, Lopez-Coronado M. Economic impact assessment from the use of a mobile app for the self-management of heart diseases by patients with heart failure in a Spanish region. J Med Syst 2014;38(9):96

21. Sterling M, Rhee H, Bocko M. Automated cough assessment on a mobile platform. J Med Eng 2014; 2014(951621).

22. Burnay E, Cruz-Correia R, Jacinto T, Sousa AS, Fonseca J. Challenges of a mobile application for asthma and allergic rhinitis patient enablement-in- terface and synchronization. Telemed J E Health 2013;19(1):13-8.

23. De La Vega R, Roset R, Castarlenas E, Sanchez-Rodriguez E, Sole E, Miro J. Development and testing of painometer: A smartphone app to assess pain intensity. J Pain 2014;15(10):1001-7.

24. Klein M, Mogles N, van Wissen A. Intelligent mobile support for therapy adherence and behavior change. J Biomed Inform 2014;51:137-51.

25. Macpherson CF, Linder LA, Ameringer S, Erickson J, Stegenga K, Woods NF. Feasibility and acceptability of an iPad application to explore symptom clusters in adolescents and young adults with cancer. Pediatr Blood Cancer 2014:61(11):1996-2003.

26. Radzuweit M, Lechner U. Introducing tablet computers into medical practice: Design of mobile apps for consultation services. Health Technol (Berl) 2014;4(1):31-41.

27. Sanger PC, Hartzler A, Han SM, Armstrong CA, Stewart MR, Lordon RJ, et al. Patient perspectives on post-discharge surgical site infections: Towards a patient-centered mobile health solution. PloS One 2014;9(12):e114016.

28. Stopczynski A, Stahlhut C, Larsen JE, Petersen MK, Hansen LK. The smartphone brain scanner: A portable real-time neuroimaging system. PloS One 2014;9(2).

29. Becker S, Kribben A, Meister S, Diamantidis CJ, Unger N, Mitchell A. User Profiles of a Smartphone Application to Support Drug Adherence - Experiences from the iNephro Project. PloS One 2013;8(10).

30. Padman R, Jaladi S, Kim S, Kumar S, Orbeta P, Rudolph K, et al. An evaluation framework and a pilot study of a mobile platform for diabetes self-management: insights from pediatric users. Stud Health Technol Inform 2013;192:333-7.

31. Haze KA, Lynaugh J. Building patient relationships: a smartphone application supporting communication between teenagers with asthma and the RN care coordinator. Comput Inform Nurs 2013 Jun;31(6):266-71; quiz 272-3.

32. Reid SC, Kauer SD, Hearps SJ, Crooke AH, Khor AS, Sanci LA, et al. A mobile phone application for the assessment and management of youth mental health problems in primary care: health service outcomes from a randomised controlled trial of mobiletype. BMC Fam Pract 2013;14:84.

33. Christensen S. Evaluation of a nurse-designed mobile health education application to enhance knowledge of Pap testing. Creat Nurs 2014;20(2):137-43.

34. DeVito Dabbs A, Song MK, Myers B, Hawkins RP, Aubrecht J, Begey A, et al. Clinical trials of health information technology interventions intended for patient use: unique issues and considerations. Clin Trials 2013;10(6):896-906.

35. Forman DE, LaFond K, Panch T, Allsup K, Manning K, Sattelmair J. Utility and efficacy of a smartphone application to enhance the learning and behavior goals of traditional cardiac rehabilitation: A feasibility study. J Cardiopulm Rehabil Prev 2014;34(5):327-34.

36. Goldberg A, Arora S, Menchine M. Patient impression and satisfaction of a self-administered, automated medical history taking device in the emergency department. West J Emerg Med 
2014;15(1).

37. Haze KA, Lynaugh J. Building patient relationships: A smartphone application supporting communication between teenagers with asthma and the rn care coordinator. Comput Inform Nurs 2013;31(6):266-71.

38. Helander E, Kaipainen K, Korhonen I, Wansink B. Factors related to sustained use of a free mobile app for dietary self-monitoring with photography and peer feedback: retrospective cohort study. J Med Internet Res 2014;16(4):e109.

39. Kuhn E, Greene C, Hoffman J, Nguyen T, Wald L, Schmidt J, et al. Preliminary evaluation of PTSD Coach, a smartphone app for post-traumatic stress symptoms. Mil Med 2014;179(1):12-8.

40. Layton AM, Whitworth J, Peacock J, Bartels MN, Jellen PA, Thomashow BM. Feasibility and acceptability of utilizing a smartphone based application to monitor outpatient discharge instruction compliance in cardiac disease patients around discharge from hospitalization. Int J Telemed Appl 2014;2014:415868.

41. Lin CY, Peng KL, Chen J, Tsai JY, Tseng YC, Yang $\mathrm{JR}$, et al. Improvements in dental care using a new mobile app with cloud services. J Formos Med Assoc 2014;113(10):742-9.

42. Min YH, Lee JW, Shin YW, Jo MW, Sohn G, Lee $\mathrm{JH}$, et al. Daily collection of self-reporting sleep disturbance data via a smartphone app in breast cancer patients receiving chemotherapy: a feasibility study. J Medical Internet Res 2014;16(5):e135.

43. Tatara N, Arsand E, Bratteteig T, Hartvigsen G. Usage and perceptions of a mobile self-manage- ment application for people with type 2 diabetes: qualitative study of a five-month trial. Stud Health Technol Inform 2013;192:127-31.

44. Tseng MH, Wu HC. A cloud medication safety support system using QR code and Web services for elderly outpatients. Technol Health Care 2014;22(1):99-113.

45. Tsui I, Drexler A, Stanton AL, Kageyama J, Ngo E, Straatsma BR. Pilot study using mobile health to coordinate the diabetic patient, diabetologist, and ophthalmologist. J Diabetes Sci Technol 2014;8(4):845-9.

46. Mira JJ, Navarro I, Botella F, Borrás F, NuñoSolinís R, Orozco D, et al. A Spanish pillbox app for elderly patients taking multiple medications: randomized controlled trial. J Medical Internet Res 2014;16(4):e99.

47. Gilliam ML, Martins SL, Bartlett E, Mistretta SQ, Holl JL. Development and testing of an iOS waiting room "app" for contraceptive counseling in a Title X family planning clinic. Am J Obstet \& Gynecol 2014;211(5):481.e1-8.

48. Guo SH, Lin YH, Chen RR, Kao SF, Chang HK. Development and evaluation of theory-based diabetes support services. Comput Inform Nurs 2013;31(1):17-26; quiz 7-8.

49. Phansalkar S, Zachariah M, Seidling HM, Mendes C, Volk L, Bates DW. Evaluation of medication alerts in electronic health records for compliance with human factors principles. J Am Med Inform Assoc 2014;Oct;21(e2):e332-40.

50. Patterson ES, Rogers ML, Chapman RJ, Render ML. Compliance With Intended Use of Bar Code
Medication Administration in Acute and LongTerm Care: An Observational Study. Hum Factors 2006;48(1):15-22.

51. Baroudi JJ, Olson MH, Ives B. An empirical study of the impact of user involvement on system usage and information satisfaction. Commun ACM 1986;29(3):232-8.

52. Freid V, Bernstein A, Bush M. Multiple chronic conditions among adults aged 45 and over: Trends over the past 10 years. Hyattsville, MD: National Center for Health Statistics; 2012.

53. Islam MM, Valderas JM, Yen L, Dawda P, Jowsey T, McRae IS. Multimorbidity and Comorbidity of Chronic Diseases among the Senior Australians: Prevalence and Patterns. PLoS One 2014;9(1):e83783.

54. Wagner EH, Groves T. Care for chronic diseases. BMJ 2002;325(7370):913-4.

55. Balogh EP, Ganz PA, Murphy SB, Nass SJ, Ferrell BR, Stovall E. Patient-centered cancer treatment planning: improving the quality of oncology care. Summary of an Institute of Medicine workshop. The oncologist 2011;16(12):1800-5.

\section{Correspondence to:}

Dr. Melissa Baysari

Centre for Health Systems \& Safety Research

Level 6, 75 Talavera Rd

Macquarie University

NSW 2109

Australia

E-mail:melissa.baysari@mq.edu.au 